\title{
SOCIAL MEDIA MARKETING AND BRANDS' SOCIAL MARKETING BEHAVIOR
}

Social media have been here in Europe for some time; all major Central European countries have their own local social networking portals - Nasza Klasa in Poland, StudioVZ in Germany, Libimseti in Czech Republic, VIPnet in Hungary, and many others. However, in Russia, except for Vkontakte, these sites are mostly non-existent. The new arrival on the block, Facebook, has created something that is worth switching to for users. Facebook has opened up its platform, allowing third parties, application developers, game developers, marketers and advertisers to build interesting content and services for its users. Facebook has really penetrated these markets; in fact, rates have gone from $10 \%$ of population in the region up to 20 - 35\% in different countries.

\section{Brands and their social media behavior}

But how are companies approaching social media today? Is their approach right? Most companies are in the social media realm today; in fact, a study by eMarketer says that over $80 \%$ of businesses are now in social media. The question is: Are they there correctly?

A study from late 2011 done by my company, Socialbakers, shows that only $15 \%$ of companies respond to questions posed by their fans and customers in the social media. That's massive! This means that $85 \%$ of companies completely ignore social media as a customer care channel, and only use it as an alternative stream for news and engagement. That's obviously not a good way to look at it, and companies that are social should really ask themselves a couple of basic questions: Are we engaging our fans in social media? Are we talking to our fans, engaging in valuable discussions? Are we proactively working with our social media to drive real value for our fans? If any of these answers are no, you are not doing it right.

There are countless examples: Skoda Auto, one of the brands that should be most social, didn't even have a social media presence until mid-2011; and since then, it has not been even basically responding to its fans in the social media. In fact, car companies around the world miss responses to questions like: „I want to buy a car this week. Which dealer is the best in the London area for this model?" Such unanswered questions could possibly even lead to discouraging the person from actually buying that company's car. Are you looking for proof that social media work? Well, if that guy didn't buy the car, it's proof that if you don't do it, you will do worse. And that just proves that if you do it right, it will have positive impact and ROI.

\section{Well, how can one measure social ROI?}

One of the most asked questions in social marketing is: "How do we measure our social ROI?” In marketing, when you do advertising and communication, you are simply expecting attention from marketers. Companies get that attention through the interest of their customers, i.e. in their interest in getting into a conversation with the brand. The customers who respond and are engaging through social media are the most important customers for you as they can bounce back and also be very positive for you. It's good that companies that have great social behavior have much greater results than companies without it.

Social networks are not only another new platform to communicate on, they are a new way of communicating with your consumers - i.e. openly, publicly. That might, of course, not appeal to some companies out there, i.e. those with 10000 rules on how they should behave internally, or those where one should not even talk about one's job online. But ultimately, we have to forget that, turn the page, and start new. Brands should use social media to get better connected with their users. That is what social is about; that is what it will always be about.

Author

Jan Řežab

CEO \& Co-Founder, Socialbakers

Dykova 12, Praha 10, 101 00, Czech Republic

jan@socialbakers.com 